\title{
What Is It Like To Be an Environment? A Semantic and Epistemological Inquiry
}

\author{
Philippe Huneman ${ }^{1} \mathbb{D}$
}

Received: 14 June 2020 / Accepted: 12 October 2021

(c) Konrad Lorenz Institute for Evolution and Cognition Research 2021

\begin{abstract}
In this article, I consider the term "environment" in various claims and models by evolutionists and ecologists. I ask whether "environment" is amenable to a philosophical explication, in the same way some key terms of evolutionary theorizing such as "fitness," "species," or more recently "population" have been. I will claim that it cannot. In the first section, I propose a typology of theoretical terms, according to whether they are univocal or equivocal, and whether they have been the object of formal or conceptual attempts of clarification. "Environment" will appear to be in a position similar to "population," yet almost no extant attempt has been made to make sense of its meaning and reference. In the second section, I will present several theoretical claims or issues that refer to "environment" in apparently very diverse ways, but always supposing a contrastive term, which is not always the same. The third section directly considers models in evolution and in ecology, and asks "where" in them is the environment term. The fourth section proposes that "environment" refers to a distinction between a varying and an invariant term, but shows that this does not exhaust its meaning, which requires making more conceptual differences. Then, I take on the suggestion that there might be two "environment" terms, one in ecology and one in evolution, but show that is not the case. Finally I center on the specific notion of "complex environment," which is the object of several research programs, and propose a typology of "complex environments" across theories.
\end{abstract}

Keywords Complexity $\cdot$ Ecology $\cdot$ Environment $\cdot$ Evolutionary biology $\cdot$ Heritability $\cdot$ Inferential role $\cdot$ Invariance $\cdot$ Model $\cdot$ Population

\section{Introduction}

Mentions of the "environment" are pervasive in anything written about evolutionary biology and ecology. It may even pervade psychology. In recent times, many papers have been devoted to the "impact of environment on IQ"; for instance, the Financial Times in 2018 asked whether "environmental factors contribute to the loss of IQ."1 And actually, reference to environment often occurs in causal questions: "is $\mathrm{X}$ due to environment or something else (genes, brain, cells etc.)?" But the fact that the form of the question pervades various domains as well as types of discourse (academic,

Philippe Huneman

philippe.huneman@gmail.com

1 Institut d'Histoire et de Philosophie des Sciences et des Techniques, CNRS / Paris I Panthéon Sorbonne, Paris, France journalistic, political, conversational) does not mean that "environment" means the same thing across those domains and language registers-in the way the meaning and reference of "moon" is indeed the same, whether it's found in astronomy or in a political speech about spatial exploration policies.

In this article I question whether "environment" means one thing or set of things, and what. More precisely, I'll wonder whether all mentions of "environment" are amenable to a particular conceptual core. And, by considering a set of conceptual distinctions pertaining to environment (complex and simple, actual and counterfactual, biotic and abiotic), as well as some particular features of models that involve mentions of environment, I'll finally claim that it is not the case.

In the first section I will explain what is this question of the core meaning, by comparing the situation of the word "environment" to other terms unavoidable in biology, such

${ }_{1}$ Financial Times, https://www.ft.com/content/b5f10c6e-68c3-11e78526-7b38dcaef614. 
as population, fitness, or gene. In the second section, I'll propose a survey of the various uses of the word "environment" in biological and ecological contexts, and suggest a categorization, by considering what is opposed or contrasted to the term "environment" in various discourses and models. The third section will directly consider various models, and ask "where" is the environment in those models; differences of structure between those models will inform us about modeling roles that "environment" can play.

In the fourth section, I'll address this categorization, proposing that the term "environment" gets its meaning first by assuming a decoupling between a varying and a nonvarying instance. The limits of this decoupling raise major issues that evolutionary biology has been facing since the $60 \mathrm{~s}$, pertaining to the relations between evolution and ecology. There, I will explicate three major distinctions through which the concept of "environment" is predicated: actual versus counterfactual, biotic versus abiotic, and cause versus partition. I'll emphasize differences between environment in ecology and in evolutionary biology, asking in the sixth section whether "environment" can be split into two terms, an ecological and an evolutionary.

In the sixth section I will center on a specific aspect of environments, namely the category of complex, unpredictable, heterogeneous ones, and the specific questions raised about those environments, which challenge a simple variant/ invariant decoupling (as a basic assumption for using the term), and points out the conceptual relation of environment to time variables. I'll conclude by a skeptical appraisal of the project of capturing what "environment" means along the lines of what has been done for the "population" concept (e.g., Millstein 2010a, b; Stegenga 2010).

This article is an exploratory work. Because few attempts of philosophically capturing a unified meaning of "environment" have been made, a major part of the work consists in surveying uses of the term and proposing meaningful distinctions to categorize those uses, with the aim of adjudicating on the feasible or unfeasible character of a conceptual analysis of the term.

\section{Terms in Scientific Discourse: A Semantic Gradient of Equivocacies}

Any scientific discourse uses a set of technical terms whose meaning is known by people in the field. The specification of the meaning is not given, but it is available to readers in the background knowledge they have when they read the text. Here I consider evolutionary biology and ecology, and argue that there exist different degrees of conceptual specification for subsets of those fields' terms. Those degrees stand on a gradient that go from the purely scientific, theoretical, and technical meanings, to a fully philosophical meaning.
To illustrate this point, consider papers in population genetics. They talk of drift, selection, fitness, QTL, polymorphism, gene flow, causes, groups, fitness, interaction, genes, species, and so on. The concepts that these terms denote have different degrees of univocity, namely of unicity of understanding among readers. And this univocity means that there exists a specification of the meaning of the term in the technical literature, hence a virtual lexicon to which anyone can be directed when wanting to know what this term means. The more this technical literature exists and converges, the more univocal is the term. So here is a scale of univocity, along which those terms can be ranged:

(a) Some terms are technical and are defined univocally: QTL, nucleotidic polymorphism, green flow, are words that elicit the same understanding in all researchers, and are also proper to the field.

(b) Other terms are technical terms, but may be equivocal, because they are used differently in different subdisciplines or schools, for example drift, variation, or migration. Biologists disagree on whether drift is a product or a process (Millstein 2006; Plutynski 2007), some of them even think that "drift" is not the whole of stochastic sampling error, and that one should distinguish environmental and demographic stochasticity; Gillespie (2004) calls for the use of "draft," a combination of changing environments and hitchhiking. "Migration" is a spatial move, but it may concern organisms or genes in population genetics, and population or species in community ecology. "Variation" is about the pattern of variation of an allele, or a trait, in a population of a species, in population or quantitative genetics. But this variation can either mean intragenerational variation, namely the distribution of variants in a population, or intergenerational variation, namely including mutations that make offspring differ from parents (Stoltzfus 2006; Huneman 2017), or both. (To some extent this may be understood in terms of the difference between processes - the mutations that create intergenerational variation - and product - the set of mutations in a population.) Biologists may debate or formally define those words, and then philosophers may also try to capture their meaning.

(c) Other terms are technical terms proper to evolutionary biology or ecology and often go without definition, even though they are absolutely crucial for many subsdiciplines. Yet, when attempts are made to clarify them, they become the core of unsolved controversies. The words fitness, genes, or species are of this kind. Some of the clarifications may include a formal apparatus especially designed, such as the account of fitness by adaptive dynamics (Metz 2008) or by Grafen's formal 
Darwinism (Grafen 2007), while others are purely conceptual. Four things are characteristic here:

- These terms receive conflicting interpretations. Thus, each take on one of these words entails a wholly different view of evolution and evolutionary biology. For instance, whoever commits to the thesis that species are individuals may think differently than an opponent about species selection and levels of selection generally, about the proper system of systematics, the relation between classification and phylogeny, and so on. And whether one adopts Fisherian fitness (Byerly and Michod 1991), fitness understood as something related to the amount of offspring (Orr 2009; Ramsey 2013), fitness as persistence (Bouchard 2011, 2013), and so on, implies that some modeling practices in population genetics will be different. Finally, the hypothesized nature of the gene will impinge on the relations between development and evolution, and more generally, on the appreciation of the role of population genetics within evolution.

- Those interpretations ultimately require taking a stand on metaphysical issues: defining fitness involves making sense of probabilities (Abrams 2012), the nature of species involves considerations about classes and individuals, and the nature of genes should be understood in relation to an account of information, ideality, and materiality (for instance, the nature of genes is information for Williams (1992), and is a sequence of DNA, hence a molecule, for others) (see Griffiths et al. 2015).

- More precisely, making sense of those words often requires both a biological argument and a metaphysical question: the nature of species (ecological versus phylogenetic versus biological concepts of species) is rather a biological issue, while the ontology of species concepts ("are they classes or individuals?") is rather a question for philosophers. Whether fitness should be ascribed to traits versus organisms, in one versus across several generations, and so on, is a question disputed by biologists, but its nature in terms of propensity versus frequency (versus other interpretations of probability) is a metaphysical issue (Mills and Beatty 1979; Abrams 2015; Drouet and Merlin 2015). However, the two sets of issues are interdependent.

- Strikingly, even though all those controversies still exist and no unanimous interpretation of those words seems ready to emerge, the researchers who use those words are able to understand each other. Maybe in some cases they talk past one another, and don't see what others are up to, but there is a strong overlap in their meaning, which implies that models and theories can be shared, tested collectively, and improved collectively.

(d) Now consider words such as "groups" or "population." They are not specifically biological, but are important in all areas of evolutionary biology (Mayr famously saw Darwinism as promoting a "population thinking"). More generally, they are not the core of a heated debate between biologists. Even though they are essentialeverybody agrees that natural selection is a populationlevel process (e.g., Millstein 2006; Huneman 2013a, b; Luque 2016) — the need for a conceptual clarification has not, or not until recently, been felt. While fitness or genes have been the target of a conceptual reflection each time evolutionary theory faced issues or new empirical advances (Hamilton 1964; Michod 1986; Ariew and Lewontin 2004; Gillespie 2004; Birch 2017), "group" or "population" were never the concern of theoreticians. But they are operational terms, in the sense that no model of population genetics or behavioral ecology can be defined without mentioning a population. It has long been implicit that the meaning of this term didn't need any additional theorizing. It goes without saying that when I say "a population," it's the members of a bird species, but not, for instance, the trees where those birds have their nests, or the symbionts that are in those birds, that we count. But what if one tries to say it?

Very recently some philosophers took on the task of making sense of populations: Godfrey-Smith (2009) asked about "Darwinian populations," even though his effort targets rather "Darwinian" than "population"; Millstein (2009, 2010a, b, 2014, 2015) targeted "population," and argued that it is a causally connected set, a bit like individuals (Huneman 2014). In response, Stegenga argued in favor of a pluralism regarding the notion of population, connected to varieties of concepts of natural selection (Stegenga 2016). Birch (2017, Chap. 4) addresses "group," and group structure via network analysis, and Barker and Velasco (2013) argued that "group" only allows for a conventionalist reading.

(e) Other terms don't have any formal definition, yet are pervasive across biology papers: for instance, process, pattern, cause, interactions. Unlike the previous ones, they are not at all especially biological. One finds them in any science. Their lack of definition may mean that one relies on the formal training of any scientist, as well as on the use of vernacular language, to make sense of them. Even though like "fitness" and similar terms, they may have distinct acceptions, and even though, also like fitness, people generally understand each other 
when they use them even without sharing converging ontologies, the differences between philosophical accounts of those words would not necessarily carry with them alternative views of evolutionary biology. It may be the case, as some people may think that the meaning of "cause" is at the heart of the controversy regarding the causal nature of selection (Reisman and Forber 2005; Huneman 2013a, b; Otsuka 2014; Walsh et al. 2017). But it is not general, and metaphysical arguments would be required here to prove that alternative takes on evolution are distinguished by rival ontologies of "process," "interaction," or "pattern." As compared to the words "fitness," "gene," and so on, or to "population" or "groups," those words require a purely metaphysical reflection, in both the sense that no proper biological concept is required for this reflection, and that such reflection has many chances to leave biology untouched.

What about environment? It is non-eliminable from any paper or book on evolutionary biology or ecology. In general, environment is, like "population," both necessary in the models and the papers while left inexplicit. As a matter of fact, the Principles of Animal Ecology, a reference book written by Clyde Allee, Thomas Park, Orlando Park, Alfred Emerson, and Klaus Schmidt in 1949, and a milestone in theoretical ecology (Allee et al. 1949), had one (of five) section wholly devoted to "The Environment." But this is very rare. "Environment" also, unlike "cause" or "interaction," is a term proper to evolutionary biology, ecology, and perhaps a few other sciences like developmental psychology-but not transversal to all sciences. Thus its elucidation, if possible, would not be of pure metaphysics, unlike "causation" or "pattern."

Hence the question: is "environment" like "population," namely, is it such that it is amenable to a conceptual clarification, despite the variety of its uses, and the fact that, whereas it's left implicit, biologists can agree with each other and understand each other when they use this term? Or is "environment" semantically different from "population," so that, even if it is a required word in models and theories, it is not amenable to one conceptual or technical and formal clarification?

To address this question, I'll consider first the variety of uses of this term across disciplines (the next section), before turning to a survey examination of models (the third section).

\section{The Environment: A Galaxy of Mentions}

Here are some claims that mention the notion of environment; they were or are important claims in evolutionary biology, ecology, or developmental biology, or in philosophical reflections about biology. They belong to different contexts, and "environment" in them may mean different things. If there exists an analysis of "environment," all those uses should be likely to be integrated in an overarching meaning. After presenting these examples, I analyze the types of meanings of "environment" present in them.

(a) Philosophers of science From the viewpoint of epistemology, many philosophers after Godfrey-Smith (1996) talk of "externalism" versus "internalism" as explanatory strategies. Externalism means "explain systems on the basis of their environment." According to Godfrey-Smith, it is what classical Darwinism or behaviorism does. Internalism, on the contrary, means "explain properties of systems on the basis of their intrinsic properties." Middle-way positions are of course frequent and Godfrey-Smith calls some of them "constructive internalism": the environmental properties here are impacted by the intrinsic properties of the system.

(b) Niche construction In a spirit close to this middle-way option, evolutionary biologists discuss a thesis that also crucially mentions "environment," namely the claim that organisms modify their environment. In evolutionary biology this is called niche construction (OdlingSmee et al. 2003): organisms impact their environment, and therefore change selective pressures on themselves and other species. Ecologists after Clive Jones talk of "ecosystem engineering" (Jones et al. 1994) and consider this property from the viewpoint of ecosystems, on an ecological timescale-even though ecosystem engineering insists on an abiotic environment while niche construction more explicitly integrates surrounding species. Actually ecology is familiar with the idea that the relation between organisms and environment is a two-way relation at least since Elton in Animal Ecology and Evolution (1930), ${ }^{2}$ who talks of a process which may be called the selection of the environment by the animal as opposed to the natural selection of the animal by the environment. In evolution there are two variables-variations of the outer environment in place and time, and variations of the characters of species in place and time. From the interaction of these two variables, adaptation has been produced. (p. 51)

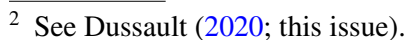


(c) Ecology More generally, ecology is the "science of the relations between organisms and their environment" (Hutchinson and Deevey 1949)—-those relations may go in whatever causal direction, and "environment" can be both biotic or abiotic, community ecology emphasizing biotic environment because of the research questions about biodiversity, while ecosystem or functional ecology doesn't privilege any aspect.

(d) Evolutionary complexity thesis In evolutionary biology, a general claim sometimes called the "environmental complexity thesis" has been at the center of discussions on the evolution of mind: mind is an adaptation for life in complex environments (Shapiro 2001). The idea here is that the complexity of mind (and, for that matter, brains) implies that it is only evolvable by natural selection in complex environments, since it would be too costly and then counterselected in simple environments; here "complex" generally means diverse, changing, and somehow unpredictable (see below on this term). The Machiavellian Intelligence hypothesis (Byrne and Whiten 1988) claims that the only environment complex enough to promote the evolution of primate brains are social environments, which explains why almost all very intelligent animals live in herds (except maybe octopuses; see Godfrey-Smith 2009).

(e) Gaia hypothesis In the domain of ecology, another important and controversial claim is the Gaia hypothesis (see Dutreuil 2014): life induces in its environment conditions that sustain habitability (Lovelock 1979). This claim has been hotly debated, and as a hypothesis it has been influential in the emergence of the research program called earth systems science (Lenton, its promoter, was a student of Lovelock (Dutreuil 2014; Lenton 2016)).

(f) Ecological crisis Ecology in general, as indicated by the definition just cited, can hardly do without mentioning "environment." This is true of the notions that connect theoretical ecology to political ecology often called "environmentalism," namely "ecological crisis," as in this quote: "many authors have claimed that the present environmental crisis is unprecedented in its magnitude, pace and severity" (from an "Environmental science and management" online course ${ }^{3}$; emphasis added).

Other notions defined as "environmental X" emerge, accompanying the phrase "environmental crisis," such as "environmental protection": "Environmental protection is a practice of protecting the natural environment on indi-

\footnotetext{
3 https://www.soas.ac.uk/cedep-demos/000_P500_ESM_K3736Demo/unit1/page_11.htm.
}

vidual, organization controlled or governmental levels, for the benefit of both the environment and humans" (ibid.).

(g) Heritability In biology, many heated debates also involve the "environment." For example, taking one of the most politically laden questions, consider the task of questioning the variance in IQ due to environment. A set of claims called the "hereditarian hypothesis" (see Comfort 2012 for a critique) picks up some studies, twin studies, and genomics in order to minimize the part due to environment, and maximize the part due to (additive genetic) variance (e.g., Plomin 2018).

This debate is very controversial because IQ touches upon issues of race, politics, and democracy, as Gould (1996) first emphasized systematically. But the question of the part of a trait variance due to environment is just a classical quantitative genetics question about any trait.

(h) $G \times E$ interactions Of course, the partition of the variance is at the center of modeling in population and quantitative genetics, and the simplifications regarding additivity done by Fisher are the heart of a major controversy regarding not only intelligence but psychology and development —as Tabery (2008) studied it. A theoretical debated issue here is precisely the weight of a term that is the variance due to (genotype*environment) interactions.

The list of such claims could go and on. I just wanted to recall that "environment" is an operational concept that is part of many of the major theoretical claims and issues in evolutionary and ecological disciplines. Because those claims are so different from each other, one may doubt that "environment" means one and only one thing, or even that all these meanings could share a tiny core of common meaning (as does "population," according to Millstein (2009, 2010a, b), Sterner (2017), or for a more pluralist view, Stegenga (2010)).

But viewing this list shows one formal thing: in all cases, "environment" is contrasted with something X. In claims about phenotypic variance on a given trait, environment is contrasted with genes. In niche construction claims, it is contrasted with organisms. In the environmental complexity thesis or the Machiavellian hypothesis it is contrasted with humans or brains. In the Gaia hypothesis, it is contrasted with life itself. In claims about ecosystems in community ecology it is contrasted with a species, or with a community of species.

This variety of contrasting terms makes it difficult to see at first what "environment" would mean in all casesexcept precisely that it is the other pole of an interaction with some of these terms mentioned above. So one could think of "environment" as a constant form of relationship between those terms and something else, hence the term 
could have a unique meaning. Yet actually, this relation is not even always an interaction: the partitioning of variance, at the heart of the quantitative genetics modeling, is precisely not an interaction, environment and the contrastive genetic term are here juxtaposed in a partition. So not only does the environment occur in contrast situations that vary across disciplines, traditions, research questions, and explanatory strategies-but, moreover, the nature of this contrast differs across occurrences.

Regarding the contrast between environments and genes or genotypes, seen in the hereditarian hypothesis, one should notice that there are two takes on this contrast, relevant to two distinct disciplines, and ultimately two aspects of the gene concept (Moss 2002; Huneman 2018): gene as a unit of inheritance, and gene as a causal factor involved in development of an organism. The latter is a causal concept, and pertains to individual organisms; the former is a populationlevel concept, because the variance is a statistical notion, always measurable in and relative to a population in an environment. The environmental part of the phenotypic variance is not the same as the causal contribution of environmental factors to the development of an organism or a trait in the organism: the latter may be very strong, while the former is extremely weak, if there is no variance in this trait in the population. Thus, even here where you have two occurrences of the contrast between the same terms, environment and genes, the nature of those contrasts is conceptually different. This makes it difficult to think of a common meaning core of the concept of "environment" underpinning all the above-mentioned uses.

In the next section, in order to search for such hypothetical core meaning and address this question, I'll consider the way this contrastive conceptual role of "environment" is realized in various theoretical models. My question here, to put it bluntly, will be: is there a common inferential function of "environment" across a set of models that would allow one to read what "environment" may mean, beyond the diversity of contrastive uses and disciplinary occurrences?

\section{Model-Based Approach: Environment and Its Contrast Term}

This approach to "environment" is model based. I'll wonder "where" the environment is in various theoretical models and their graphical representations. To anticipate, we'll find that here again it's hard to pinpoint one modeling role of the concept. This section will make heavy use of graphical representations, because they allow one to view where exactly the environment stands in the functioning of the model. But the diagram only visualizes what is the functioning of the "environment" term in the model.

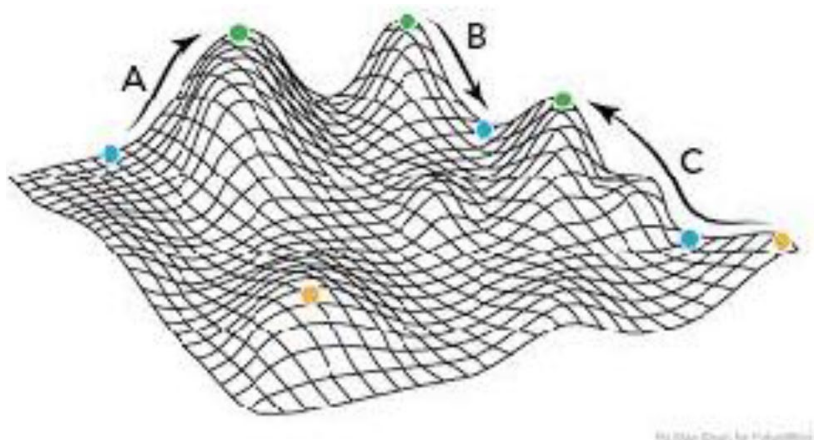

Fig. 1 A fitness landscape. Vertical axis is fitness, horizontal axes are allele frequencies, or alleles for a given locus. Peaks are local or global fitness optima (Wikipedia Commons)

(a) In population genetics, a pervasive tool is the "fitness landscape" (Wright 1932; for a critical appraisal see Svensson and Calsbeek 2013; Okasha 2018, Chap. 4; for an epistemic approach to recent uses of the model, Huneman 2018).

Fitness landscapes have been introduced by Sewall Wright as tools to model visually the question of adaptive evolution in populations where many epistatic interactions make it difficult for natural selection to increase fitness by changing alternatively both alleles of a genotype. If there are two alleles on two loci, $\mathrm{X}, \mathrm{x}$ and $\mathrm{Y}, \mathrm{y}$, and writing $(\mathrm{W}(\mathrm{ab})$ the fitness of the genotype ab) $\mathrm{W}(\mathrm{xy})<\mathrm{W}(\mathrm{XY})$, but $\mathrm{W}(\mathrm{Xy})<\mathrm{W}(\mathrm{xy})$ and $\mathrm{W}$ $(x Y)<W(x y)$, then, when the population initially is constituted of (xy) genotypes, a change of one of the alleles would involve a decrease in fitness and then not be selected. So the model represents the action of natural selection as hill climbing, in this case going "down" from $\mathrm{xy}$ to $\mathrm{xY}$ or Xy and then up to another peak XY (Fig. 1).

Leaving aside all controversies about the meaning of the landscape (which may model both the fitness of allele combinations in each organism, so that the population is a cloud of points, or the fitness of alleles distributions in a population, so that the population is just a point ${ }^{4}$ ), let's see where the "environment" is here. It is not "in" the landscape, of course: environment is represented by the fitness axis. The environment is present here only through the fitness values, which register how each possible population or each possible organism fares with regard to environmental demands (in terms of a specific measure of evolutionary success, often related to offspring number).

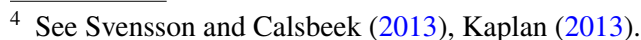




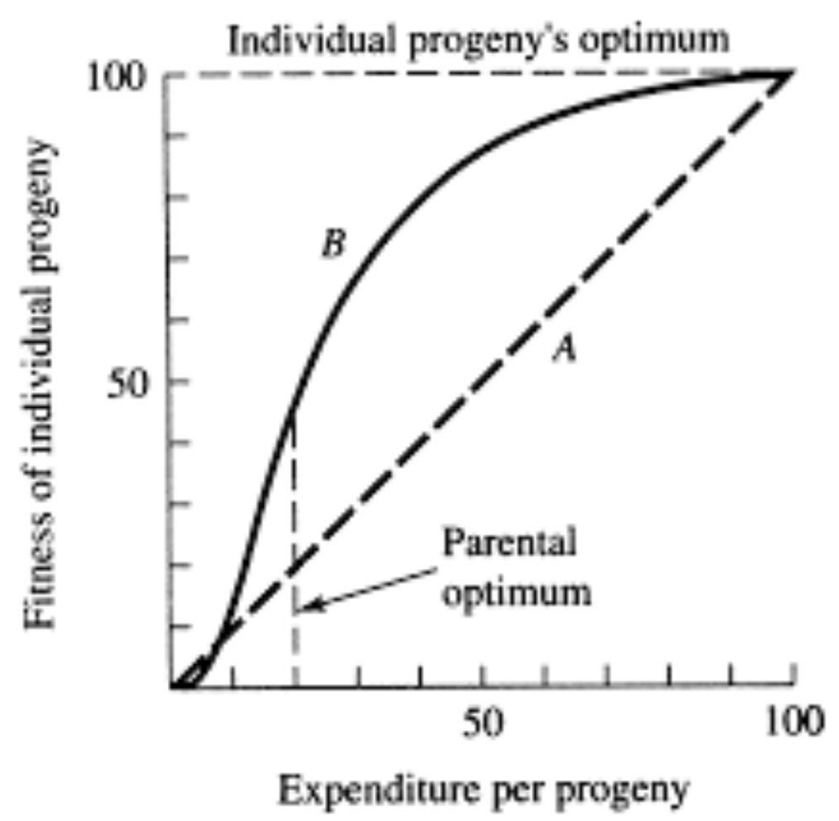

Fig. 2 An optimality model, which models parental investment in progeny (Wikipedia commons)

(b) Now, let's consider behavioral ecology-the science that intends to explain traits and behaviors as adaptations, hence as strategies optimal in the environment because they maximize a proxy for fitness (Krebs and Davies 1995) —or more generally as results of natural selection. (Hence, the whole field is deemed to be prima facie adaptationist.)

Behavioral ecology has been under focus from the controversies over adaptationism started by Gould and Lewontin's (1979) famous spandrel paper (Mayr 1983; Grafen 1984; Godfrey-Smith 2001; Lewens 2009). These authors contested that one could hypothesize that traits are adaptations, and then build a model according to which they appear as fitness-maximizing answers to environmental demands. More recently, behavioral ecology has been the focus of attempts to reconcile its organism-based explanations of traits with the genebased view of the mechanisms of evolution, modeled by population and quantitative genetics (Grafen 2007; Huneman 2014; Birch 2016).

Notwithstanding the answers to those two controversies, which concern the limits of methodological adaptationism and the legitimacy of what Grafen (1984) called "phenotypic gambit" (namely, the idea that reasoning on fitness maximizing by phenotypes generally corresponds to the way genetic frequency change will bring to fixation some phenotypes), I wonder about the way environment stands in these models.

Behavioral ecology distinguishes two cases: frequency-independent, when various trait values or strategies undergo a fitness payoff independent of the frequency of all trait values, and frequency-dependent, when the fitness payoff of any strategy depends upon what other organisms do, which is also called strategic interactions (Fig. 2).

(b1) In the first case, optimality models appear as functions that link trait values to fitness, or more generally a proxy for fitness such as calorie intake, metabolism rate, and so on. Some of the most famous objects of these models were foraging time and clutch size. Lack (1947) initiated the field by explaining that clutch size, which was mostly around four to five each season independently of the populations of birds, was governed by selection at the individual level (see Kimler 1986; Borrello 2003).

The expected trait value is the one where the curve of this function reaches its maximal value. Here, as in the case of population genetics, environment occurs in an implicit way-it is present via the fitness value. But this is more complex because:

- First, what is represented is rather a proxy for fitness, and the whole modeling depends upon a hypothesis regarding the best proxy chosen in the given environment. So environment is what codetermines (with the nature of the trait) the robustness of a proxy choice, because not any environment allows for measuring the same properties as correlated with fitness.

- Second, the function itself is determined by what environmental demands are taken as relevant to the evolution of the trait under focus. So the fitness axis somehow represents the environment, but only as a shortcut or snapshot of this environment because only the relevant environmental demands are used to compute fitness.

The choice of a proxy, as well as the possibility of hypothesizing novel environmental demands to fix a gap between model expectations and the data, are often cited by the critiques of adaptationism as two reasons why those models are not falsifiable. But in any case, the model explains traits as adaptations in an environment by implicitly representing the environment through the use of a fitness function.

Hence, environment functions implicitly as what one could call a background variable in these two kinds of models, populations genetics (a) and (nonstrategic) behavioral ecology (b1).

(b2) Consider now frequency-dependent traits, such as the game of Hawks and Dove which was the first major paradigm for behavioral ecology of frequency-dependent traits. Maynard-Smith (1982) coined the concept of "evolutionarily stable strategy," ESS, as a strategy 


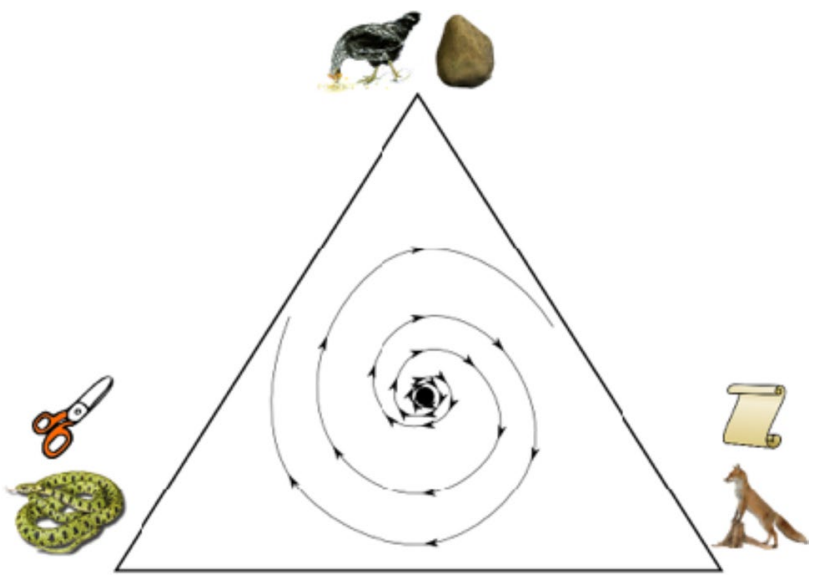

Fig. 3 Model of a frequency-dependent selection: rock-scissors-paper game in a phase space (from https://www.science4all.org)

which is such that once the population adopts it, it cannot be invaded by any mutant strategy.

In those cases, organisms don't evolve towards optimal traits, but towards ESS strategies. See a model of rock-paper-scissors (by Kerr et al. $(2002)^{5}$ ): in this game, rock beats (in fitness payoff) scissors but not paper, scissors beats paper but not rock, and paper beats rock but not scissors. Technically, no strategy is dominant, so the payoff of each strategy depends upon the probability of the two other strategies, hence of the frequencies of all strategies within a population. This can be modeled in a phase space where each point is a state of population defined by the frequency of the three strategies (Fig. 3). So, interestingly in this model there is apparently no environment. The transition between states of the populations depends upon the payoffs of each strategy, which depend upon the previous state of the population.

Each organism has all other organisms as environments. But for a strategy one could then think of each environment as a frequency compound of the two other strategies (because such compound determines the payoffs of this strategy at this moment). Yet the replicator's dynamics, which is the name of this kind of model, evacuates the environment from the model: what appears is a purely intrinsic dynamics.

Hence in this case it seems that even though the environment plays a role in explaining at each step the steepness of the trajectory in the phase space, there is no presence of the environment, even implicit, in the model itself. This shows that regarding the status of the

5 And see the general theory of replicator's dynamics which is used in these models in Hofbauer and Sigmund (1998).

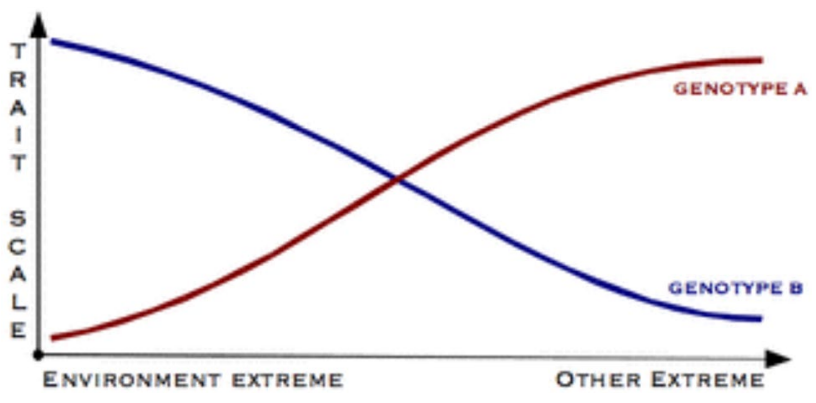

Fig. 4 The reaction norm of two genotypes (Wikipedia Commons)

environment optimality modeling in behavioral ecology seems closer to population genetics (both have an implicit presence of the environment term) than to ESS modeling in behavioral ecology. ${ }^{6}$

Yet, on the contrary, other kinds of models, instead, make "environment" directly explicit. That is first the case of reaction norms in population genetics.

(c) A reaction norm $(\mathrm{RN})$ - a notion stemming from Woltereck (1909) (see Sarkar 1999)—is the function that connects phenotypic expression of a given gene or genotype $g$ to environmental parameters $E$ : $N_{g}=f$ (E). So here, "environment" - or at least an environmental parameter-is precisely the horizontal axis of the graph. The phenotypic expression may be a concentration in a substrate, or a measurable phenotypic feature. The curve can be linear, or have thresholds and plateaus. As has often been said, the mere existence of reaction norms debunks any "genetic determinism," since the phenotype depends upon both environment and the genotype (Fig. 4).

Reactions norms are a way to model something more general, which is phenotypic plasticity-namely the fact that phenotypes may vary, given the same genotype. Even though plasticity is much richer than reaction norms (Nicoglou 2015), these are an aspect of this concept, which historically intended to capture an interaction between environment and organisms. Yet RN are ascribed to genotypes rather than organisms.

An important aspect of RN has been emphasized by proponents of Developmental Systems Theory (Griffiths and Knight 1998) under the name of "causal parity" (Oyama 2000). While we talk of RN about a gene, one could also consider an environmental feature $\mathrm{E}$,

\footnotetext{
${ }^{6}$ Of course this doesn't exhaust all models in behavioral ecology or game-theoretical behavioral ecology. My point consists in giving an idea of how the "environment" term works across models, even though I don't have room to analyze all types of models in each discipline; I just intend to give a sense of the diversity of these roles.
} 

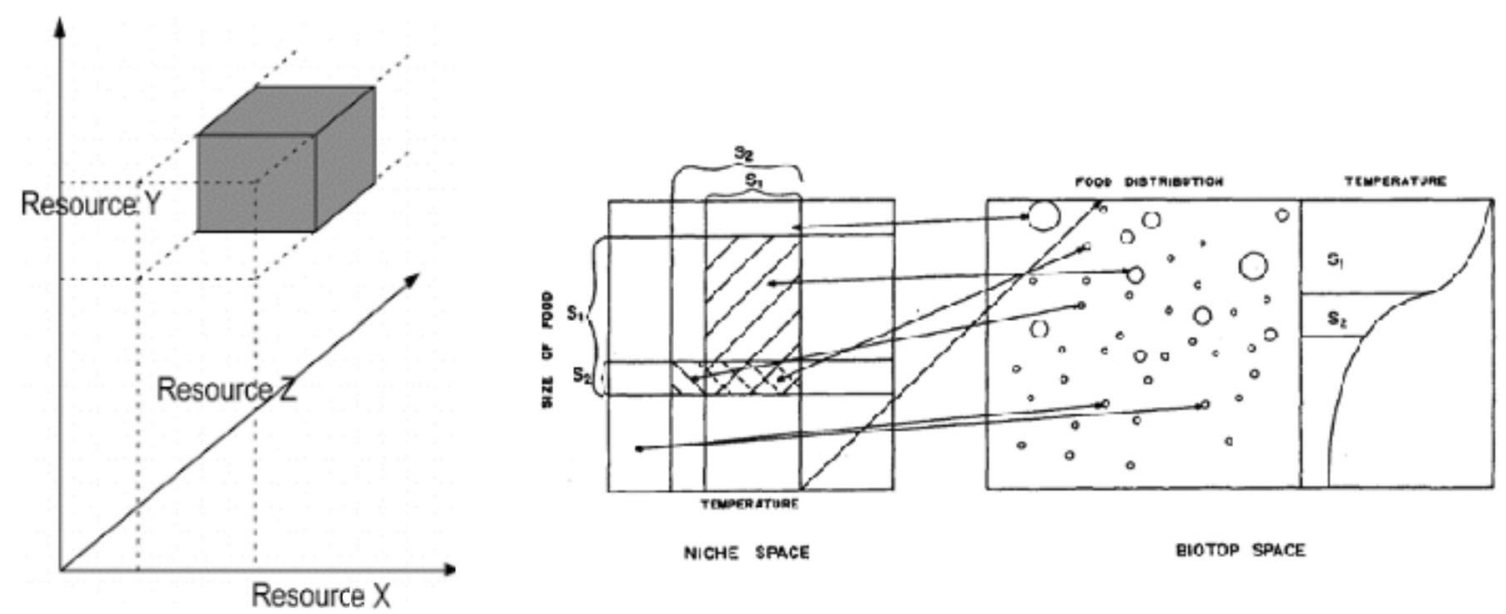

Fig. 5 The ecological niche. Right, Hutchinson diagram of a fundamental and realized niches in a parameter space and in a biotope (Hutchinson 1957); left, a fundamental niche based on three resources $\mathrm{x}, \mathrm{y}, \mathrm{z}$

and consider its "reaction norm" $\mathrm{N}_{\mathrm{e}}=\mathrm{f}(\mathrm{G})$-namely, for a given environment $\mathrm{E}$, consider the function that states which phenotype is expressed, depending upon which genotype $\mathrm{G}$ is in $\mathrm{E}$. This would, so to say, reverse the proper reaction norm, and it is logically possible.

A philosophical issue then is about why we almost never consider what environments' reaction norms would be. Granted, reaction norm per se is not figuring causation but correlation. So, here, one may think that the relation between genotype and phenotype in a given environment is causal, and that the reverse is not true, which makes the standard reaction norm more meaningful or useful than $N_{e}=f(G)$. However, undoubtedly, the environment is one cause of a phenotype. Some philosophers after Maynard-Smith (2000) have concurred on the claim that what is specific about the reaction norm of the genotype is that the gene-phenotype relation is informational, in addition to being causal. Shea (2011), for example, elaborated a sophisticated theory of information that supports such a claim; Griffiths et al. (2015) proposed an interpretation of specificity that does this, and allows for more than DNA strands as informational supports.

However, the environment may be less prone to reaction norms for two pragmatic reasons: controllability, and mathematical tractability. First, if environmental parameters are the average temperature or $\mathrm{pH}$ in the field, it's plausible that manipulating gametes or genes will be easier to do. Second, more importantly, because the differences between genes are discrete (DNA differences mostly), the modeling of reaction norms is much more mathematically tractable than modeling the reaction norms of the environment, where it would be hard to identify which parameters' values are supposed to allow relevant reaction norms.

The metaphysics of causation and information first mentioned were additional reasons to think that genotypes' reaction norms are more reliable and relevant than the environment's reaction norms. But the dissymmetry is enough established by pragmatic reasons of tractability and control. Reversibility is important because it shows that "environment" is a term behaving differently in these models, where it's explicit, than in population genetics (a) or optimality models (b1): the latter models, where environment is an implicit term, are not in principle reversible. So the theoretical structure of the variable relative to environment and the concept of environment are different in these two kinds of models, (a, b1) or RN.

(d) Now, considering ecology, we'll witness another aspect of the explicit role of environmental terms.

Community ecology makes a major use of the concept of a niche. When modeling biodiversity, "niche" is a key concept because it allows ecologists to ask why the species are present where they are, and why do these species coexist. Niche is part of the answer-an answer eventually tracing back to natural selection. For the classical theory of biodiversities, revolving around this paradigm of niches (Hutchinson 1957; MacArthur and Levins 1967; Tilman 1982) coexisting species (in a community) are species that have separate niches. Nowadays this niche model of biodiversity is rivaled by the so-called neutral model of biodiversity, championed by Hubbell (2001)—but the neutralist idea preexisted Hubbell, and was already formulated by MacArthur and Wilson (1967), which models the biodiversity in 
"islands" on the assumption that the fitness of species, hence selection, plays no role, only dispersal governs the emergence of biodiversity (Fig. 5). ${ }^{8}$

Notwithstanding this major theoretical divide (Mouquet, McGill (2010), Hubbell, Rampal, etc.), I consider here the ecological concept of a niche and the role played by "environment" in this theoretical construct and in the models that are based on it.

The classical ecological niche concept was elaborated by Hutchinson, even though it has an important history, and that Grinnell and then Elton (1927) gave different versions of this concept in different contexts (Pocheville 2015). For Hutchinson, a "niche" is a property of a species, rather than of geographical space. ${ }^{9}$ It does not exist in real physical space, but in an abstract space whose axes are the parameter values of the environment, for instance, $\mathrm{pH}$, moistness, temperature, nitrate level, potential amount of predators, and so on.

The niche of a species therefore results from two considerations: the viability space of the species, namely the range of parameters in which it is able to thriveand then, the competition with species that share part of the same viability space. The former defines the "fundamental niche," where the species can be; the second determines the "realized niche," in which it can actually be found. Where the two fundamental niches of two species overlap, the better competitor wins and excludes the other. This is the so-called "competitive exclusion principle" (Weber 1999). Thus, to explain the biodiversity in an ecosystem, ideally one would partition the ecosystem into realized niches that don't overlap, and each species would stand in its niche. In practice, it is different especially because realized niches are reached after a competitive process, which assumes that the whole environment and other species remain constant; if they don't, equilibrium is not reached, and actual biodiversity may depart from expectations. ${ }^{10}$ Of

\footnotetext{
7 "Islands" is a theoretical and not a geographical term; any territory lacking communication avenues for organisms with other territories is an "island."

8 On the "ecological equivalence hypothesis" formulated by Hubbell (2001), which is a radicalization of Wilson and MacArthur's hypothesis, see Chave (2004), Munoz and Huneman (2016).

${ }^{9}$ For the context of the elaboration of this concept in the concluding remarks of the Cold Spring Harbor 1957 symposium on population biology, which hosted an important controversy between proponents of a density-dependent regulation of abundances, and of densityindependent regulation, see Huneman (2019). Hutchinson's niche is a sophisticated concept, and one can argue that besides the canonical reading I present here, Hutchinson in some contexts integrated elements from the geographical space (Colwell and Rangel 2009).

10 This is how Hutchinson explains the "paradox of the plankton," namely the fact that there exist many more plankton species than
}

course, the current theories are much more complex, but the core intuition is still the role played by the twolayered concept of niche.

Environment is a constitutive concept of the niche models. It is represented, in the model, as the niche parameters. Notice that one actual environment only occupies a part of the hyperspace (because it is characterized by only a range of all parameter values). Fundamental niches are defined in a hyperspace in which several environments are represented (each defined by their parameter values). For a given species, in the model environments therefore occur twice: first as a range of parameter values of its fundamental niche, and second, as the set of other realized niches that neighbor its realized niche. The two-layered concept of niche therefore goes with a two-faceted role of "environment" in niche modeling, namely, the species's environment minus its competitors (fundamental niche) and the actual environment with the competitors (realized niche).

The lesson of this examination is that here the inferential role of "environment" and its modeling use differ from what happens either in explicit models of RN, or in explicit models of population genetics and behavioral ecology: it is more explicit than in behavioral ecology, and more like RN, because parameters are represented in the graph, but it is much more complex, since it has this two-layered structure.

(e) To be coherent with the claims I selected above, let's consider a last model, used in the discussions over the Gaia hypothesis. Here, the two variables are "life," and "environment." Each one affects the others, and the model shows that the feedback exerted by life onto environmental conditions makes the actual values of "environment" capable of remaining in the domains where life is possible (namely, fosters "habitability" of Earth - this is the core claim of Gaia (Dutreuil 2014)) (Fig. 6).

The "environment" term is such that a property of "life," namely, what one could call its "amount," is a function of the environment, and because there is an interaction between the two terms, the model features a two-way relation. The role of "environment" is explicit, but more complex than in the case of RN because it is at the same time an explanandum and an explanans. Also, environment is related to "life," not directly to species, organisms, or genes, so the level of abstraction here differs from other models considered before, and

\footnotetext{
Footnote 10 (continued)
}

expected on the basis of the sole competitive exclusion principle (Hutchinson 1961). 
Fig. 6 A model in the context of the Gaia hypothesis; the feedback of life (L) on environment (E, on the horizontal axis)

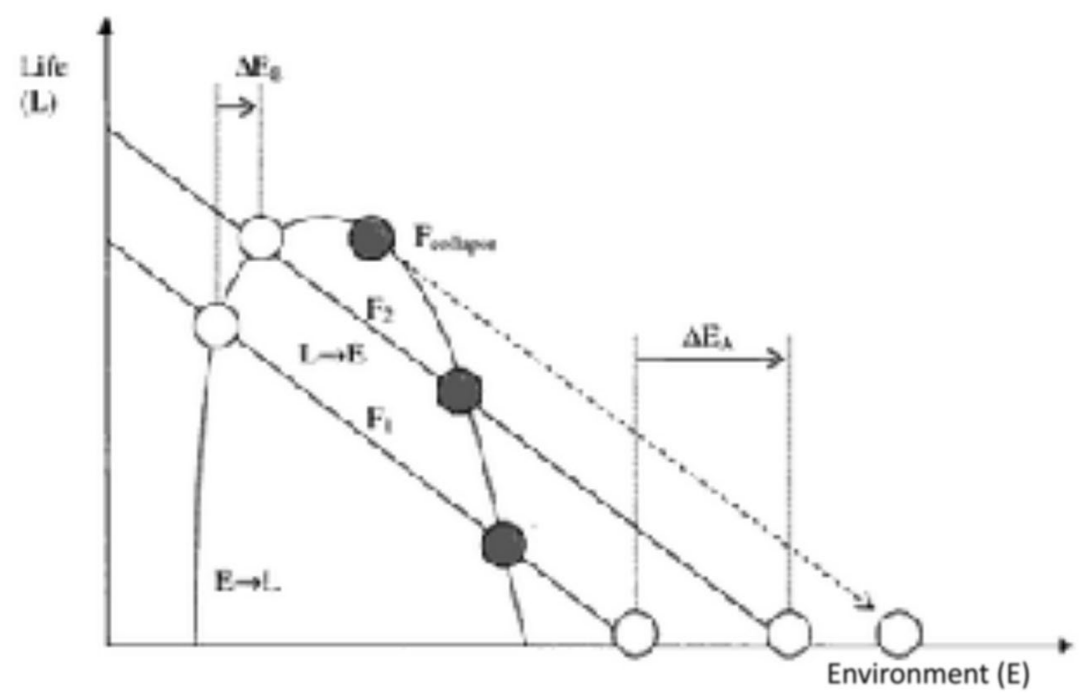

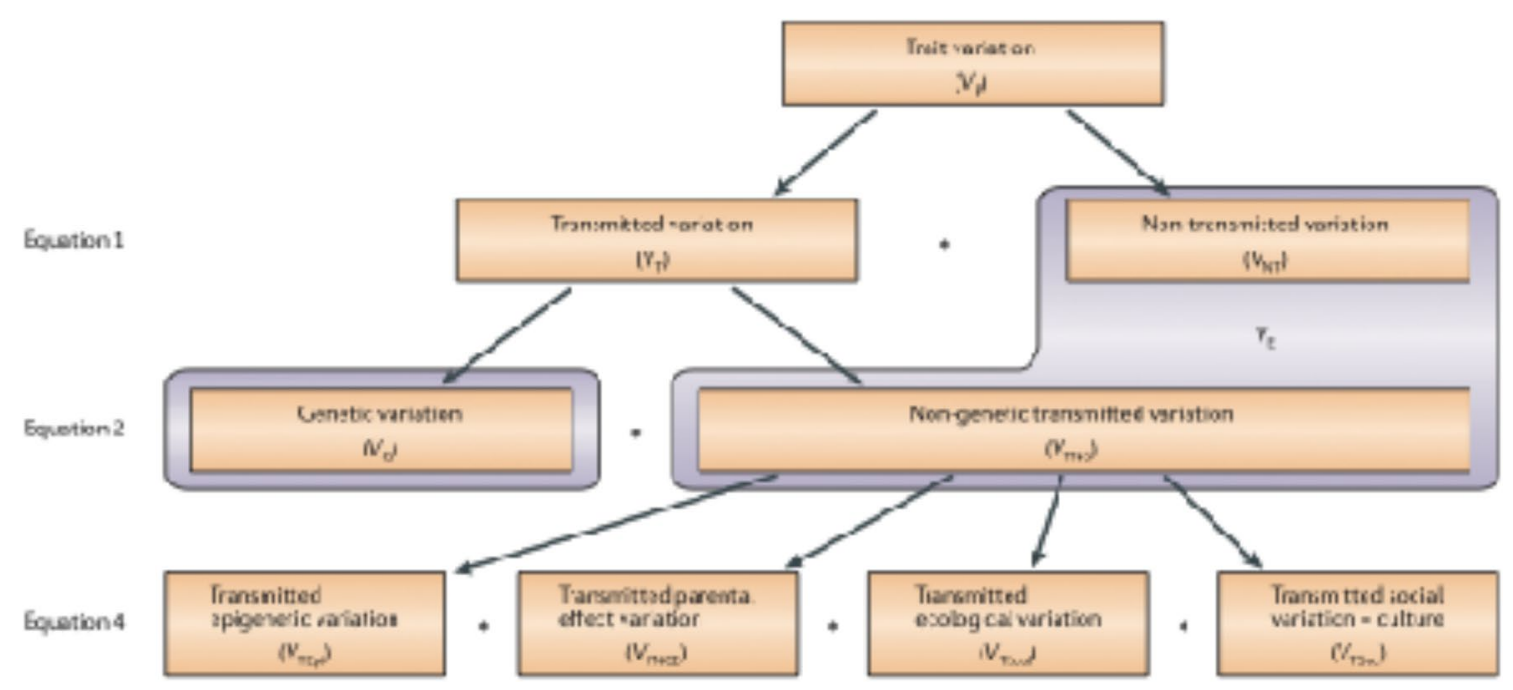

Fig. 7 Partitioning the phenotypic trait variance to measure heritability in the context of "inclusive inheritance" (Danchin et al. 2011)

especially from the complicated role it plays in niche modeling seen above, where environment has a twolayered status. More precisely, there are "species," in the sense of various metabolic types variously affecting the overall environmental parameters. But those parameters are mostly like $\mathrm{pH}$ or temperature $\mathrm{T}$, not resources consumed by competing species. And this environment is always shared and global; it is a kind of homogenous chemical atmosphere that is affected by and affecting each metabolic type. Niche construction models present the same kind of two-way relation between environment and contrast term $\mathrm{X}$-here, the organism-but because of the nature of this contrast term, their level of abstraction is lower (see Dutreuil and Pocheville 2015 for a comparison between niche construction models and Gaia modeling). (f) Now, look at heritability studies: what is the "environment" term doing here? Let's consider this representation of the partition of the variance in an article arguing that not all variance heritable is genetic (Danchin et al. 2011) (Fig. 7). I leave aside this last claim, but only look at the form of the representation, and what "environment" does here. Environment is represented by the box "variance due to environment"-and it's juxtaposed with "transmitted variance." In this particular case, "environment" has two inferential roles in the model: it contrasts with a non-environmental variance (1) and it is the locus of a question about the decomposition of the environmental variance into distinct components (2). Juxtaposition here contrasts with a causal relation, as when researchers question the respective causal contributions of genes and environments to 
the development of a phenotype (see above about the partition versus causation distinction), or with a correlational relation (as is the case in RN). The major question is not here correlating (with phenotypes), or causing (phenotypes), but partitioning (the phenotype, its variance), and the environmental term is both the result (1) and a locus (2) of a partitioning.

Let's summarize what we've seen. Models refer to the term "environment" but it occupies very different inferential roles in those models. While we saw that "environment" always goes with contrast claim terms, the variety of its inferential roles do not map onto the variety of its contrastive terms. For instance, while Gaia models have "environment" as a term that contrasts with "life," which is a very unique feature across models, "environment" here functions as an explicit term, as in other models such as reaction norms or niche models. The relevant difference between models is, first, the explicit/implicit distinction. Then, among models conferring "environment" an explicit inferential role, Gaia, $\mathrm{RN}$, or niche models present some differences.

To conclude this short examination, we saw that not only the contrastive term of "environment" is important, in questions such as "is it more environment than X?"- -but also the structure of the model and the role/position of the environment term: implicit versus explicit, one-way versus two-way, and causation versus partitioning (or juxtaposition). This second kind of diversity, visible in models, makes it difficult to find a common core of meaning of the term environment, because when one looks at models, there is not one general articulation between "environment" and its contrastive claim term X that would characterize what "environment" means. Therefore this diversity of functioning in models, which exceeds the simple distinction implicit/explicit, is another reason why giving a unified account of what "environment" means in evolution and ecology, and what it does in modeling practices, may not be possible-or at least appears to be very difficult.

In the next section I will focus on a pragmatic distinction that is used in most of these models, even though it doesn't mean that the "environment" term is specifically positioned regarding this distinction; on the contrary, once again we'll find varieties in the conceptual role of the notion.

\section{The Variant/Invariant Distinction-and the Limits of a General Characterization}

What the environment means cannot be captured independently of the two features identified above: the contrastive term in the claims, the way the model behaves regarding the explicit/implicit distinction. This leads to an interpretative hypothesis: "environment" does not refer to one thing, as even "population" or "fitness" do, but to a modeling structure, which connects an X to something else in a specified relation with $\mathrm{X}$, and this specified relation determines the "meaning" of "environment," understood as the inferential role played by the term in a specific modeling structure. Such a specified relation prima facie always holds between variant and invariant terms. I will now explore this suggestion.

\section{"Environment" as Correlated to the Variant- Invariant Distinction}

To start with, saying that a trait $\mathrm{X}$ results from natural selection on population $\mathrm{O}$ in environment $\mathrm{E}$ means that the population evolves towards a trait value $\mathrm{X}$ determined by the environment as the best response to environmental demands. "Externalism" as an explanatory strategy is, more generally, an operation that considers environment as an invariant term, and the explanandum as a possibly variant term, which will get fixed via the process of natural selection. This distinction between variant and invariant relies on objective features of systems, while "implicit versus explicit" are primarily features of models of the systems.

However, this relation between variant and invariant isn't exactly the same across all roles environment plays in models. In fitness landscapes, for instance, the "environment" is not a varying term, because the fitness values are given, allowed to define the fitness surface, and are determined by the environment. More generally in implicit models, "environment" is not a varying term. What varies are, precisely, the genotypes, phenotypes, alleles, or allele frequencies. Considering behavioral ecology, environment is implicitly present in fitness terms, and here too, it is invariable. But in explicit models, things are different. In reaction norms, there is a variation of environmental parameters, as well as in the case of niche models, and also in ESS models (even though those parameters are not present as such in the model).

Yet this is of course too quick. The first complication is that a fitness landscape may include change of environment, because the change in allele frequency may impinge on the fitness values of all alleles-frequency-dependence in fitness landscapes makes them seem rather like "seascapes," namely landscapes that change in the same time as the organisms or population in the landscape changes (Mustonen and Lässig 2009).

Many evolutionary models focus on evolution in changing environments. But environments are always changing, to some extent. The timescale difference is therefore what is relevant here: when one assumes that environment is invariant while traits, organisms, or genotypes vary, this means that the changing speed of the environment is much slower than the changing speed of organisms or genes. Distinguishing variant and invariant amounts to a decoupling assumption between timescales (see Pocheville 2018 for a theory of 
Fig. 8 Optima and niche in the context of changing environments (Levins 1962)

\begin{tabular}{|c|c|c|c|}
\hline & \multirow{2}{*}{$\begin{array}{c}\text { Niche difference } \\
\text { small compared } \\
\text { to tolerance }\end{array}$} & \multicolumn{2}{|c|}{$\begin{array}{c}\text { Niche difference large compared } \\
\text { to tolerance }\end{array}$} \\
\hline & & $\begin{array}{c}\text { Environment stable } \\
\text { in time, variable } \\
\text { in space }\end{array}$ & $\begin{array}{c}\text { Environment uniform } \\
\text { in space, variable } \\
\text { in time }\end{array}$ \\
\hline Optimum phenotype & Intermediate & $\begin{array}{l}\text { Optimum in more } \\
\text { common niche }\end{array}$ & $\begin{array}{l}\text { Optimum for either } \\
\text { niche }\end{array}$ \\
\hline Optimum population & $\begin{array}{l}\text { Monomorphic and } \\
\text { unspecialized }\end{array}$ & $\begin{array}{l}\text { Monomorphic and } \\
\text { specialized }\end{array}$ & $\begin{array}{l}\text { Polymorphic, with } \\
\text { specialized types }\end{array}$ \\
\hline $\begin{array}{l}\text { Optimum geographic } \\
\text { pattern }\end{array}$ & Continuous cline & Discrete races & $\begin{array}{l}\text { Cline in frequencies } \\
\text { of specialized } \\
\text { types }\end{array}$ \\
\hline
\end{tabular}

timescale decoupling). Thus, evolution in a changing environment means that the changing pace of the environment is comparable-even if slower-to the evolutionary rhythm of the population.

\section{The Variant-Invariant Distinction and the Difference Between Evolution and Ecology Regarding "Environment"}

A consequence concerns the relations between ecology and evolution. Even though those two fields are intertwined, because ecology is about the conditions for the operation of natural selection (the "science of the struggle for existence," as Haeckel famously said), while evolution accounts for the species by dominantly considering the action of natural selection, their interrelation has always been difficult (Collins 1986; Kingsland 1995; Huneman 2019). This difficulty revolves around the fact that microevolution often assumes some constancy of the environment, meaning that the surrounding species are relatively constant (around the focal species), while ecology questions the change of species (the making of biodiversity patterns, the ecological successions, etc.). This shows how the notion of "environment" differs, at first sake, between ecology and evolution. However, this timescale difference does not exhaust the whole difference between ecology and microevolution since some ecological processes are as fast as evolutionary processes-this coupling of speed was detected in the 1960s. Microevolutionary processes can be coupled to evolutionary processes.

The accumulating evidence of the evolutionary synthesis and post-synthesis research yielded a fuller understanding of the rate of evolutionary change. [...] The repeated demonstration of "microevolution" forced a reduction in the amount of time thought to be required for at least some kinds of evolutionary change. This reduction condensed what H. J. Muller called "evolutionary" time to the timescale of some ecological processes. (Collins 1986, p. 275)
Levins's work on fitness in changing environments explored this situation with major consequences on the concept of fitness and the need to differentiate two kinds of fitness values, coarse-grained and fine-grained fitness functions. Nowadays, "eco-evolutionary feedback" (Kokko and López-Sepulcre 2007; Hendry 2016) is at the core of novel attempts to unify ecology and evolution (I'll come back to this issue in the sixth section). Evolution in a changing environment also means "spatial changes." Levins distinguishes two kinds of "changing": across time while environment is stable across space, or the contrary (Fig. 8). This gives rise to distinct fitness functions, as well as distinct predictions for epistemic optima.

Another important difference concerns the cause of the environmental change: it may be the ecology, in the sense that the set of ecological interactions between individuals of various species in the community results in change of biodiversity patterns that occur at the same pace as phenotypic changes evolutionarily driven in the population. But it can also be the mere effect of evolution in the population, which changes each phenotype's frequency, and then the nature of the environment faced by each individual. External ecologydriven and internal evolution-driven environment change are not incompatible and may often occur simultaneously.

But the scale difference isn't enough to understand how the "variant/invariant" distinction becomes operational in evolutionary and ecological theorizing. One should also rely on the distinction between actual and counterfactual environments, as I explain now.

\section{Which Variations? Counterfactual Versus Actual Environments}

Considering reaction norms, the variations of environment that are plotted on the graph are not always actual variations, if one considers a given allele or genotype that is studied. The set of variant phenotypes mapped are also counterfactual phenotypes, because in the specific case studied there will be one actual phenotype. In the same way, let's consider 
another explicit model, namely the ecological niche. What is actual, when one looks at the community, is the realized niche. The fundamental niche is counterfactual, it is the niche of the species without competing species, so in a world when competitive exclusion has not occurred. Now, the values of the environmental parameters of the hyperspace can be actual or not. A given environment often does not feature all values of the relevant environmental parameters. The range of those parameters, like in $\mathrm{RN}$, therefore extends across counterfactual environments. But here, there is a second level of counterfactual reasoning, namely the fundamental niches.

This difference between actual and counterfactual environments is also relevant in the case of adaptationist explanations, and finally in any externalist explanatory strategies. Written as a function relation between $\mathrm{O}$ (organism) and $\mathrm{E}$ (environment) an adaptationist explanation states $\mathrm{O}=\mathrm{f}(\mathrm{E})$; that formula is criticized by Lewontin (2000) because he pinpointed the causal action done upon the environment by the organisms, which eventually change their environmentas developed by the biologists who study niche construction (Odling-Smee et al. 2003; Pocheville 2018). But this function $\mathrm{f}$ supposes a variation across counterfactual environments. The actual organism, $\mathrm{O}_{\mathrm{O}}$, is one value of possible organisms, and those organisms are related to counterfactual states of the environment. The actual environment $\mathrm{E}_{\mathrm{O}}$ is conditioning and explaining the actual organism $\mathrm{O}_{\mathrm{O}}=\mathrm{f}$ $\left(\mathrm{E}_{\mathrm{O}}\right)$, but the fact that Lewontin expressed the explanatory relation in this functional way makes clear that "environment" occurs twice in the explanation, both as an actual environment (which is invariant), and as a set of counterfactual environments (to which the variation of possible organisms are correlated).

\section{Limits of the Variant-Invariant Distinction to Account for the Meaning of the Term "Environment"}

More generally, the variant/invariant distinction is not the whole picture about environment in explanatory strategies. Heritability measures connect two kinds of variation, the environmental and the genetic one (see the next section); there is no "invariant" term here, and the question is not about causal dependance, but partitioning variance, so the environment and $\mathrm{X}$ terms are related as two complements, components of the whole variance, not two functionally or causally related terms.

However, the varieties of uses of "environment" in models are not exhausted by those distinctions. The distinction between fundamental and realized niches brings to the fore another distinction, namely between the biotic versus abiotic environments. Fundamental niches are generally defined by
Table 1 Summarizing differences in the way the structuring distinction variant/invariant works in evolutionary and ecological theorizing

Variant/invariant: functional/causal relation

Variance: partition

Actual (environment) Counterfactual (environments)

Biotic/abiotic

Timescale differences

the abiotic environment, in addition to the preys (environmental parameters are often resources). Adding the rest of the biotic environment allows for competition, and therefore determines the realized niches. In the Gaia models, the "environment" is opposed to "life"- therefore it is by definition "abiotic."

Hence, the typology of models that I draw, including explicit and explicit modeling as well as contrasting terms, led us to recognize that one major distinction first structures the conceptual use of "environment": the variant/invariant difference on the one hand; the variance-to-be-partitioned, on the other. Within the class of variant/invariant terms, there are two uses of environment: the invariant actual environment, or the range of counterfactual environments. Two major distinctions should be made within the first class: biotic versus abiotic environments, and then, distinctions of timescales allowing variance decoupling (see Table 1). Like variant versus invariant, those distinctions are primarily predicated on systems themselves, rather than models (unlike the implicit/explicit distinction commented above).

Hence there is not one single modeling role for "environment"; it can't refer to one kind of thing; it has many definitions, and they can't be sorted out by using formalizations-because, for instance, the formalization would assume distinguishing variant and invariant terms, which already drops one conceptual role of "environment." I'm thus very skeptical about the possibility of giving a conceptual analysis of "environment," either verbal or formal, as has been done for "population" by Millstein $(2009,2015)$ or Stegenga (2010, 2016), even though Stegenga argues for a pluralism regarding "population." I don't even think the variety of concepts and roles of "environment" is coherent enough to allow for some pluralism.

Yet there might be two ways (not incompatible) to go here, if one wants to explicate further what "environment" means. The first way consists in focusing on the pair evolution versus ecology, and trying to see whether some meaning of environment can be given in each of the fields, so that ultimately "environment" refers to two different things in these two fields. The second way consists in focusing on one question about environments, likely to allow a more substantial meaning of "environment" to be detected; this option was mentioned when I considered the "environmental complexity thesis" and when I looked at the eco-evolutionary 
couplings-namely, it concerns the semantics of complex, unpredictable, changing environments. The two following sections will address those issues successively.

\section{Ecology and Evolution: Are There Two Distinct Notions of Environment?}

While ecology has been sometimes defined as "the science of the interactions between organisms and environment," Darwinian biology, according to Godfrey-Smith (1996), is an instance of externalist explanation, which explains the systems - the organisms - on the basis of their environment (via natural selection). "Environment" seems therefore to be a key term in those gross characterizations of the two fields of inquiry. While the first field seems to include a two-way relation, the second thinks in terms of a one-way relation (which is exactly constituted by "externalism"). This may explain why ecologists like Elton have been thinking of the phenomena that evolutionists now call "niche construction" much earlier than evolutionists-at least since Elton (1930), cited above.

Because of the plurality of model structures and contrastive items examined before, the quest for a "core meaning" seems disappointing to me. This promotes the idea of looking for a few distinct core meanings of the term. Hence the idea of looking at the difference between evolution and ecology in order to find two core references for "environment." More precisely, examining the ways the concept of natural selection is explanatory in the ecological niche and in population genetics models may indicate some topical differences between ecology and evolution that go beyond the timescale differences, and then overcome the possible issue raised by timescale coupling. I will therefore now consider this dual take on natural selection.

Thinking of a fundamental niche, the major parameters to conceive of it are resource parameters of the environment. Therefore, competition and dispersion are two distinct processes that theoretically occur "after" the description of the fundamental niche. They are not on the same theoretical level; hence, the environment of the species appears twice in the construction of the niche model, once at the level of the fundamental niches in terms of mostly abiotic conditions and preys, second at the level of the realized niches, in terms of competition, i.e., biotic environment. From the viewpoint of evolutionary biology, on the other hand, if one considers the microevolution of a species, all these parameters-resources, competition, dispersion-are part of the selective pressures, thus they are on a par: in principle, all of them equally contribute to fitness values.

Thus ecological environment appears as bidimensional (biotic, and abiotic, those two levels of environment somehow corresponding to fundamental and realized niches, even though the predation and mutualism relations pertain to fundamental niche) while in evolution it seems unidimensional (in the sense that all of the ecological dimensions are environmental demands adding up to fitness values). In the former, several interactions appear, which structure the relations between species, and between species and environments: predation, mutualism, and then competition, dispersion, ecosystem engineering. In the latter, those interactions pile up into a specific force, "natural selection," which adds up to other population level forces-migration mutation and drift (Sober 1984). Even though the force reading of selection and drift is the object of a heated debated in philosophy of biology (Stephens 2004; Bouchard and Rosenberg 2004; Abrams 2007; Huneman 2013a, b; Earnshaw 2015; Luque 2016; Walsh et al. 2017; Desmond 2018; etc.), this sketchy characterization suggests that at the level of evolution the specificities of ecological interactions with resources and species in the environment are lumped into what evolutionary biologists call forces or factors. From an epistemological viewpoint, in ecology, the organism and its species live in an environment structured by ecological interactions; in evolutionary biology, the organisms and their species are shaped by forces that are made up of those interactions, and then add up with other forces such as drift or mutations. Hence, they are not exactly in the same conceptual kinds of environment (even if one thinks it's the same physical environment).

Brandon (1990) convincingly argued that evolutionists are interested in what he calls "selective environments" rather than physical or external environments. Selection is an individualizing factor for environments in the sense of evolutionary biology. That is, selective pressures are factors that differentially impact on individuals in a species: if a factor, namely an ecological force, affects all individuals in the same way, no matter their genetic constitution, then it's not relevant for natural selection (Huneman 2015). Hence it is not part of the "environment." This implies that some of the interspecies competition is wholly irrelevant for evolution, since all members of the focal species are equally concerned by this competition. From the moment all individuals are identically affected by this competition, no selection happens. However, such interspecific competition in ecology is exactly what determines a realized niche, hence it is a major interaction occurring within ecological environments.

So, together with the unidimensional versus bidimensional character of environments, the relevance or irrelevance of interspecies competition in ecology versus in evolution is a key difference between "environment" in those two fields. Thus, have we captured two distinct meanings of "environment" in them?

Things are not so simple. This difference masks the fact that ecologists and evolutionists may talk of the same thing, but from distinct viewpoints, as an example will make clear. The two-way relation between environment and some $\mathrm{X}$ has 
triggered much attention in the last fifteen years; now "niche construction" means the effect of organisms on environments. Yet, ecologists have recently seen another kind of interaction, namely "facilitating interactions." Species A facilitates species B when A increases the abundance of B; this can be done, for instance, by diminishing the abundance of $\mathrm{C}$ through predation when $\mathrm{C}$ is a competitor of $\mathrm{B}$. The overall effect of facilitation is that, in terms of niche, the fundamental niche is extended rather than diminished, hence the realized niches are not necessarily smaller than the fundamental niches, thanks to facilitators, as it has been argued (Bruno et al. 2003). ${ }^{11}$ "Niche construction," by changing selective pressures, is exactly a process through which facilitations may happen. Therefore, ecological and evolutionary models handle the same kind of processes, but the latter handles it through the concept of selection while the former sees it through the concept of niche. Clearly, if "environment" referred to two different things in ecology and evolution, this situation, and the theoretical exchanges that are occurring there, would be impossible. Finally, the apparent differences in "environment" between two disciplinary fields may go along with several other similar cases where a same set of phenomena falls under a different concept and involves different implications in ecology and in evolutionary biology.

Even though the provisory conclusion of this exploration is that there is no common reference to "environment" across evolution and ecology but no easy way to separate two meanings for the term, one may hope to find a substantial meaning of "environment" when one holds it to a set of issues, those denoted by the label "complex environment," where complex means diverse, unpredictable, changing, stochastic, and so on-since a large class of questions involving "the environment" are about such environments, as for instance is attested to by the "environmental complexity thesis" (Shapiro 2001).

Whatever "environment" means, complexity of environments is a side-effect of the merging of evolutionary and ecological timescale. When the two timescales, of environmental and evolutionary change, get close to one another, then environment becomes "changing": species with which the individuals of the focal species interact change, which changes the fitness values of the traits simultaneously with the change in the population, according to fitness values. This timescale coupling therefore generates complexity, in the sense that environments and then evolutionary change become heterogeneous across time and less predictable.

The last section of this article explores the varieties of the roles played by "complex" environments in research

\footnotetext{
11 Even if the position is contested and should be mitigated (Rodriguez-Cabal et al. 2012).
}

programs, and attempts a short conceptual analysis and typology.

\section{Focusing on "Complex" and "Unpredictable" Environments}

"Complex" environments have a particular status in evolutionary biology. Adaptation to such environments is assumed to be the key of any account of the emergence of mind, intelligence, or reflection. Large brain is a proxy for those faculties, and the brain is indeed metabolically costly, so selection should have had a life-saving reason for maintaining those organs at such a cost.

To see why, let's start with a more simple and general adaptation for some environmental complexity-plasticity: phenotypic plasticity would not be favored by natural selection if an environment were very simple, so that there were only one optimal phenotype, no matter the time of the year. Hence, assuming all conditions for adaptationism (see Birch 2016; Okasha 2018 for those conditions) are given, this phenotype would be the one favored by natural selection.

If the environment is varying, then plastic behavior may do better than another, less plastic, one, assuming that the organism detects cues through which it can change its phenotype according to distinct states of the environment. Suppose now that the cues are numerous and weakly correlated with environmental states. In this case, it may be advantageous to evolve a decision-making module that computes the probability of states on the basis of a combination of cues. Hence, if one views this kind of environment as "more complex," as would be plausible according to many notions of complexity, it can be argued that mind-which includes high predicting capacities-evolves as a response to complex environments.

So, even though the very meaning of "complexity" is far from consensual, and hard to formally characterize (Adami 2002), here we have grades of complexity in environments: (a) simple, (b) varying with cues, and (c) unpredictable. Those levels of complexity select for different kinds of traits in organisms. This whole idea can legitimately be termed the "environmental complexity thesis." The (b) kind of complexity is studied in general by Levins (1968) and biologists who took on this research program. It can show heterogeneity in both space and in time. Complexity as unpredictability (c) is another grade of time heterogeneity.

Complex "environment" here covers a core meaning, namely: something opposed to organism, in relation to it, structured and changing, offering cues predictive of some of those changes, those cues having coevolved with detecting capacities from the side of the organism. And this complexity comes in degrees. 
Ecological and evolutionary environmental complexities may then be distinguished according to the source of the heterogeneities. Ecological complexity pertains to the succession of species in the ecosystem as well as the dynamics of abiotic factors. This heterogeneity is often the target of studies of "evolution in changing environment" after Levins's seminal work. But there is also an evolutionary heterogeneity induced by frequency-dependent changes of population composition (see the previous section), hence the notion of "complex" environment is two-faceted, since it comes from both ecological heterogeneity and evolutionarily driven heterogeneity.

According to my above considerations, evolution and ecology often occur on different timescales, which allows modelers to do a decoupling between their processes. But the two timescales can merge, as has been studied increasingly after Levins in the 60s. As was emphasized, "changes of both kinds may be on any time scale: frequently genetic and ecological changes are simultaneous"' (Antonovics 1976, p. 241). The complexity of those eco-evolutionary feedbacks requires merging specific modeling tools, and therefore constitutes another grade of complexity, and another notion of complex environment, beyond the grade (c) that concerns unpredictability generaliter. This is not taken into account by the "environmental complexity thesis," and a next research question inspired by this thesis should focus on whether there is something specific that evolves from such intertwined ecological-evolutionary complexity.

\section{Conclusion}

This article offered a semantic and epistemic exploration of the uses of the concept of "environment" and its place and role across modeling practices by ecologists and evolutionists of various kinds. It addressed one question: is "environment" a term amenable to conceptual analysis, formal specification, or philosophical interpretation in the way terms like "population" have been? My provisory answer is no. There seems to be no really unified concept of environment, besides the strategy of decoupling some varying and unvarying terms in order to address some questions. There exists no sufficient formal definition that would embrace at the same time the uses of the environment term in causal ascriptions, in partitioning tasks (heritability), and in correlations (RN, etc.).

"Environment" appears as a pragmatic term, likely to make sense in a specific context because it is univocally used in a model, and likely to be mentioned and understood in larger contexts so that it promotes understanding between scientists and research programs, even though the detailed modeling practices are different. There will be no theory or concept of "the environment" capable of unifying evolution and ecology, but people can talk to each other and communicate results when they both mention "environment."

Yet some typological differences between modeling uses of environment can be made. And then, a set of research questions that involves both evolution and ecology centers around the notion of "complex" environment, "complex" denoting features that are diverse: heterogeneity, change, low predictability - and that come in degrees. The range of issues to be addressed here includes the "environmental complexity thesis," which opens up major questions regarding the evolution of humankind and the relations between primates, but also less explored questions pertaining to the interplay between ecology and evolution.

\section{References}

Abrams M (2007) How do natural selection and random drift interact? Philos Sci 74:666-679

Abrams M (2012) Mechanistic probability. Synthese 187(2):343-375

Abrams M (2015) Probability and manipulation: evolution and simulation in applied population genetics. Erkenntnis 80(S3):519-549

Adami C (2002) What is complexity? BioEssays 24(12):1085-1109

Allee WC, Park O, Emerson AE, Park T, Schmidt KP (1949) Principles of animal ecology. W. B. Saunders Company, Philadelphia

Antonovics J (1976) Plant population biology at the crossroads. Input from population genetics. Syst Bot 1:234-245

Ariew A, Lewontin RC (2004) The confusions of fitness. Br J Philos Sci 55:347-363

Barker M, Velasco J (2013) Deep conventionalism about evolutionary groups. Philos Sci 80(5):971-982

Birch J (2016) Natural selection and the maximization of fitness. Biol Rev 91(3):712-727

Birch J (2017) The philosophy of social evolution. Oxford University Press, Oxford

Borrello ME (2003) Synthesis and selection: Wynne-Edwards' challenge to David Lack. J Hist Biol 36:531-566

Bouchard F (2011) Darwinism without populations: a more inclusive understanding of the "Survival of the Fittest." Stud Hist Philos Biol Biomed Sci 42(1):106-114

Bouchard F (2013) What is a symbiotic superindividual and how do you measure its fitness? In: Huneman P, Bouchard F (eds) From groups to individuals. Evolution and emerging individuality. MIT Press, Cambridge, p 243

Bouchard F, Rosenberg A (2004) Fitness, probability and the principles of natural selection. Br J Philos Sci 55:693-712

Brandon R (1990) Adaptation and environment. MIT Press, Cambridge

Bruno JF, Stachowicz JJ, Bertness MD (2003) Inclusion of facilitation into ecological theory. Trends Ecol Evol 18:119-125

Byerly HC, Michod RE (1991) Fitness and evolutionary explanation. Biol Philos 6(1):45-53

Byrne RW, Whiten A (1988) Machiavellian intelligence. Oxford University Press, Oxford

Chave J (2004) Neutral theory and community ecology. Ecol Lett $7: 241-253$

Collins JP (1986) Evolutionary ecology and the use of natural selection in ecological theory. J Hist Biol 19(2):257-288

Colwell R, Rangel T (2009) Hutchinson's duality: the once and future niche. PNAS 106(2):19651-19658 
Comfort N (2012) The science of human perfection: how genes became the heart of American medicine. Yale University Press, New Haven

Danchin É, Charmantier A, Champagne FA, Mesoudi A, Pujol B, Blanchet $S$ (2011) Beyond DNA: integrating inclusive inheritance into an extended theory of evolution. Nat Rev Genet 12:475-486

Desmond H (2018) Selection in a complex world: deriving causality from stable equilibrium. Erkenntnis 83(2):265-286

Drouet I, Merlin F (2015) The propensity interpretation of fitness and the propensity interpretation of probability. Erkenntnis 80(S3):457-468

Dussault AC (2020) Funtionalism without selectionism: Charles Elton's "functional" niche and the concept of ecological function. Biol Theory. https://doi.org/10.1007/s13752-020-00360-9

Dutreuil S (2014) What good are abstract and what-if models? Lessons from the Gaia hypothesis. Hist Philos Life Sci 36(1):16-41

Dutreuil S, Pocheville A (2015) Les organismes et leur environnement: la construction de niche, l'hypothèse Gaïa et la sélection naturelle. Bulletin de la Société d'Histoire et d'Épistémologie des Sciences de la Vie 22(1):27-56

Earnshaw E (2015) Evolutionary forces and the Hardy-Weinberg equilibrium. Biol Philos 30(3):423-437

Elton C (1927) The ecology of animals. Wiley, New York

Elton C (1930) Animal ecology and evolution. Clarendon Press, Oxford

Gillespie J (2004) Population genetics. Oxford University Press, New York

Godfrey-Smith P (1996) Complexity and the function of mind in nature. Cambridge University Press, Cambridge

Godfrey-Smith P (2001) Three kinds of adaptationism. In: Orzack SH, Sober E (eds) Adaptationism and optimality. Cambridge University Press, Cambridge, pp 335-357

Godfrey-Smith P (2009) Natural selection and Darwinian populations. Oxford University Press, New York

Gould SJ (1996) The mismeasure of man. Norton, New York

Gould SJ, Lewontin R (1979) The spandrels of San Marco and the Panglossian paradigm: a critique of the adaptationist programme. Proc R Soc Lond B 205:581-598

Grafen A (1984) Natural selection, kin selection and group selection. In: Krebs JR, Davies NB (eds) Behavioural ecology. Blackwell, Oxford, pp 62-84

Grafen A (2007) The formal Darwinism project: a mid-term report. J Evol Biol 20:1243-1254

Griffiths P, Knight RD (1998) What is the developmentalist challenge? Philos Sci 65(2):253-258

Griffiths P, Pocheville A, Calcott B, Stotz K, Kim H, Knight R (2015) Measuring causal specificity. Philos Sci 82(4):529-555

Hamilton WD (1964) The genetical evolution of social behaviour I and II. J Theor Biol 7(1):1-52

Hendry AP (2016) Eco-evolutionary dynamics. Princeton University Press, Princeton

Hofbauer J, Sigmund K (1998) Evolutionary games and population dynamics. Cambridge University Press, Cambridge

Hubbell SP (2001) The unified neutral theory of biodiversity and biogeography. Princeton University Press, Princeton

Huneman P (2013a) Assessing statistical views of natural selection: is there a room for non local causation? Stud Hist Philos Biol Biomed Sci 44(2013):604-612

Huneman P (2013b) Causal parity and externalisms: extensions in life and mind. Mind Mach 23(3):377-404

Huneman P (2014) Individuality as a theoretical scheme. I. Formal and material concepts of individuality. Biol Theory 9(4):361-373

Huneman P (2015) Inscrutability and the opacity of natural selection and random genetic drift: distinguishing the epistemic and metaphysical aspects. Erkenntnis 80(S3):491-518

Huneman P (2017) Variation, extension and selection: a synthesis of the reasons for a new evolutionary synthesis. In: Huneman P,
Walsh D (eds) Challenging the modern synthesis. Development, inheritance and adaptation. Oxford University Press, New York, pp 68-110

Huneman P (2018) Neutral spaces and topological explanations in evolutionary biology: lessons from some landscapes and mappings. Philos Sci 85(5):969-983

Huneman P (2019) How the modern synthesis came to ecology. J Hist Biol 52(4):635-686

Hutchinson GE (1957) Concluding remarks. Cold Spring Harb Symp Quant Biol 22:415-427

Hutchinson GE (1961) The paradox of the plankton. Am Nat 95:137-145

Hutchinson GE, Deevey ES Jr (1949) Ecological studies on populations. In: Avery GS Jr (ed) Survey of biological progress. Academic Press, New York, pp 325-359

Jones C, Lawton J, Shachak M (1994) Organisms as ecosystem engineers. Oikos 69:373-386

Kaplan J (2013) Adaptive landscapes: concepts, tools and metaphors, the adaptive landscape in evolutionary biology. Stud Hist Philos Biol Biomed Sci 44(4):613-616

Kerr B, Riley M, Feldman M et al (2002) Local dispersal promotes biodiversity in a real-life game of rock-paper-scissors. Nature 418:171-174

Kimler WC (1986) Advantage, adaptiveness, and evolutionary ecology. J Hist Biol 19:215-233

Kingsland SE (1995) Modeling nature: episodes in the history of population ecology. University of Chicago Press, Chicago

Kokko H, López-Sepulcre A (2007) The ecogenetic link between demography and evolution: can we bridge the gap between theory and data? Ecol Lett 10:773-782

Krebs JR, Davies N (1995) Behavioral ecology: an evolutionary approach. Blackwell, London

Lack D (1947) The significance of clutch-size. Ibis 89:302-352

Lenton T (2016) Earth system science: a very short introduction. Oxford University Press, Oxford

Levins R (1962) Theory of fitness in a heterogeneous environment. I. The fitness set and adaptive function. Am Nat 96:361-373

Levins R (1968) Evolution in changing environments. Princeton University Press, Princeton

Lewens T (2009) Seven types of adaptationism. Biol Philos 24(2):161-182

Lewontin R (2000) The triple helix-gene, organism and environment. Harvard University Press, Cambridge

Lovelock J (1979) Gaia: a new look at life on Earth. Oxford University Press, Oxford

Luque VJ (2016) Drift and evolutionary forces: scrutinizing the Newtonian analogy. Theoria 31(3):397-410

MacArthur RH, Levins R (1967) The limiting similarity, convergence, and divergence of coexisting species. Am Nat 101:377-385

MacArthur RH, Wilson EO (1967) Theory of island biogeography. Princeton University Press, Princeton

Maynard Smith J (1982) Evolution and the theory of games. Cambridge University Press, Cambridge

Maynard Smith J (2000) The concept of information in biology. Philos Sci 67(2):177-194

Mayr E (1983) How to carry out the adaptationist program. Am Nat 121:324-334

McGill BJ (2010) Towards a unification of unified theories of biodiversity. Ecol Lett 13(5):627-642

Metz JAJ (2008) Fitness. In: Jørgensen SE, Fath B (eds) Evolutionary ecology, vol 2. Elsevier, Oxford, pp 1599-1612

Michod RE (1986) On fitness and adaptedness and their role in evolutionary explanation. J Hist Biol 19(2):289-302

Mills S, Beatty J (1979) The propensity interpretation of fitness. Philos Sci 46(2):263-286 
Millstein RL (2006) Natural selection as a population-level causal process. Br J Philos Sci 57(4):627-653

Millstein RL (2009) Populations as individuals. Biol Theory 4(3):267-273

Millstein RL (2010a) Should we be population pluralists? A reply to Stegenga. Biol Theory 5(3):271-276

Millstein RL (2010b) The concepts of population and metapopulation in evolutionary biology and ecology. In: Bell MA, Futuyma DJ, Eanes WF, Levinton JS (eds) Evolution since Darwin: the first 150 years. Sinauer, Boston

Millstein RL (2014) How the concept of population resolves concepts of environment. Philos Sci 81(5):741-755

Millstein RL (2015) Thinking about populations and races in time. Stud Hist Philos Biol Biomed Sci 52:5-11

Moss L (2002) What genes can't do. MIT Press, Cambridge

Munoz F, Huneman P (2016) From the neutral theory to a comprehensive and multiscale theory of ecological equivalence. Q Rev Biol 91(3):321-342

Mustonen V, Lässig M (2009) From fitness landscapes to seascapes: non-equilibrium dynamics of selection and adaptation. Trends Genet 25(3):111-119

Nicoglou A (2015) The evolution of phenotypic plasticity: genealogy of a debate in genetics. Stud Hist Philos Biol Biomed Sci 50:67-76

Odling-Smee J, Laland K, Feldman M (2003) Niche construction. The neglected process in evolution. Princeton University Press, Princeton

Okasha S (2018) Agents and goals in evolution. Oxford University Press, Oxford

Orr HA (2009) Fitness and its role in evolutionary genetics. Nat Rev Genet 10:531-539

Otsuka J (2014) Causal foundations of evolutionary genetics. Br J Philos Sci. https://doi.org/10.1093/bjps/axu039

Oyama S (2000) Causal democracy and causal contributions in developmental systems theory. Philos Sci 67(3):347

Plomin R (2018) Blueprint: how DNA makes us who we are. Allen Lane, London

Plutynski A (2007) Drift: a historical and conceptual overview. Biol Theory 2(2): 156-167

Pocheville A (2015) The ecological niche: history and recent controversies. In: Heams T, Huneman P, Lecointre G, Silberstein M (eds) Handbook of evolutionary thinking in the sciences. Springer, Dordrecht, pp 547-586

Pocheville A (2018) A Darwinian dream: on time, levels, and processes in evolution. In: Uller T, Laland K (eds) Evolutionary causation: biological and philosophical reflections. MIT Press, Cambridge

Ramsey G (2013) Organisms, traits, and population subdivisions: two arguments against the causal conception of fitness? Br J Philos Sci. https://doi.org/10.1093/bjps/axs010
Reisman K, Forber P (2005) Manipulation and the causes of evolution. Philos Sci 72:1113-1123

Rodriguez-Cabal MA, Barrios-Garcia MN, Nuñez MA (2012) Positive interactions in ecology: filling the fundamental niche. Ideas Ecol Evol 5:36-41

Sarkar S (1999) From the reaktionsnorm to the adaptive norm: the norm of reaction, 1909-1960. Biol Philos 14(2):235-252

Shapiro L (2001) Mind the adaptation. In: Walsh D (ed) Naturalism, evolution and mind. Royal Institute of Philosophy Supplement 49. Cambridge University Press, Cambridge, pp 23-41

Shea N (2011) What's transmitted? Inherited information. Biol Philos 26(2):183-189

Sober E (1984) The nature of selection. MIT Press, Cambridge

Stegenga J (2010) "Population" is not a natural kind of kinds. Biol Theory 5(2):154-160

Stegenga J (2016) Population pluralism and natural selection. Br J Philos Sci 67(1):1-29

Stephens C (2004) Selection, drift and the "forces" of evolution. Philos Sci 71:550-570

Sterner B (2017) Individuating population lineages: a new genealogical criterion. Biol Philos 32(5):683-703

Stoltzfus A (2006) Mutationism and the dual causation of evolutionary change. Evol Dev 8:304-317

Svensson E, Calsbeek R (2013) The adaptive landscape in evolutionary biology. Oxford University Press, Oxford

Tabery J (2008) R. A. Fisher, Lancelot Hogben, and the origin of genotype environment interaction. J Hist Biol 41(4):717-761

Tilman D (1982) Resource competition and community structure. Princeton University Press, Princeton

Walsh D, Ariew A, Matthen M (2017) Four pillars of statisticalism. Philos Theory Pract Biol. https://doi.org/10.3998/ptb.6959004. 0009.001

Weber M (1999) The aim and structure of ecological theory. Philos Sci 66(1):71-93

Williams GC (1992) Natural selection: domains, levels and challenges. Oxford University Press, Oxford

Woltereck R (1909) Weitere experimentelle Untersuchungen über Artveränderung, speziel über das Wesen quantitativer Artunterschiede bei Daphniden. Verhandlungen der deutschen zoologischen Gesellschaft 19:110-173

Wright S (1932) The roles of mutation, inbreeding, crossbreeding and selection in evolution. In: Proceedings of the sixth annual congress of genetics, vol 1. pp 356-366

Publisher's Note Springer Nature remains neutral with regard to jurisdictional claims in published maps and institutional affiliations. 